\title{
ANALISIS TINGKAT PENDAPATAN MASYARAKAT NELAYAN SOMA PAJEKO DI KECAMATAN SALIBABU KABUPATEN KEPULAUAN TALAUD SULAWESI UTARA
}

\author{
Siska Salatan ${ }^{1^{\star}}$, Victoria E. N. Manoppo ${ }^{2}$, and Suria Darwisito ${ }^{2}$
}

${ }^{1}$ Program Studi Magister IImu Perairan, Fakultas Perikanan dan IImu Kelautan, Universitas Sam Ratulangi. Jln. Kampus Unsrat Bahu, Manado 95115, Sulawesi Utara, Indonesia

${ }^{2}$ Fakultas Perikanan dan IImu Kelautan, Universitas Sam Ratulangi. JIn. Kampus Unsrat Bahu, Manado 95115, Sulawesi Utara, Indonesia Koresponden e-mail: salatansiska@gmail.com

\begin{abstract}
Talaud Islands Regency includes maritime territory, $94.6 \%$ of which is waters directly adjacent to the Philippines and holds a variety of high economic living resources. In North Sulawesi Provincial Regulation Numbered 1/2017, article 12 concerning Zoning Plan of Coastal Zone and Small Islands of North Sulawesi Province 2017-2037, Talaud Islands Regency is designated as Integrated Marine and Fisheries Center Location of Talaud. It is located in Salibabu district, where Regional Regulation of Spatial Plan Numbered 1/2014 concerning Spatial Plan of Talaud Islands Regency for 2014-2034, Salibabu District is prioritized for Fishing Fisheries Regional Development and Management since its unutilized fisheries potential is still about 23,104 tons/year. In 2017, Salibabu district occupies the highest order for total fisheries production in Talaud Islands District. It was 702.3 tons or $11.79 \%$ of that in Talaud Islands Regency, $46.23 \%$ of which were gained from purse seines. Majority of the purse seine fishermen are those whose main livelihoods are fishermen and do not have other jobs. Fishing community is, in general, a relatively lagging community group socially, economically and culturally when compared with other community groups. The purse seine fishermen community in Salibabu district, in fact, still has mean income far below the minimum wage of Kabupaten Talaud, IDR. 1,500,000, -. The purse seine fisherman community in Salibabu district is still chained with poverty and backwardness. Therefore, there are needs for external intervention as an incentive to empower them in order to get out of the situation.

This study used descriptive method, a method of studying the recent status of human groups, an object, a set of condition, a system of thinking or a class of events. Data collection consisted of primary and secondary data. It was done through in-depth interviews, filling questionnaires and literature studies. Respondents were purse seine fishermen communities in Salibabu district. Data analysis used descriptive method to know the socio-economic life of the communities and income formula to analyze the income level of fishermen purse seine.

Results showed that mean net income in Salibabu district was approximately IDR 86,784,000/year for the purse seine owner and IDR.10,608,840/year for fishing crews, respectively, with main catches of skipjack tuna, mackerels, and scads.
\end{abstract}

Keywords: Purse seine fisherman, Salibabu District and Income level of Fisherman

\begin{abstract}
Abstrak
Kabupaten Kepulauan Talaud termasuk wilayah bahari dimana 94,6\% wilayahnya adalah perairan yang berbatasan langsung dengan negara Philipina dan memiliki sumberdaya hayati yang bernilai ekonomis tinggi. Dalam Peraturan Daerah Provinsi Sulawesi Utara No. 1 tahun 2017 pasal 12 tentang Rencana Zonasi Wilayah Pesisir dan PulauPulau Kecil Provinsi Sulawesi Utara tahun 2017-2037, Kabupaten Kepulauan Talaud ditetapkan sebagai lokasi Sentra Kelautan dan Perikanan Terpadu. Lokasi tersebut terletak di Kecamatan Salibabu, dimana pada Perda RTRW (Rencana Tata Ruang Wilayah) No. 1 Tahun 2014 tentang Rencana Tata Ruang Wilayah Kab. Kepulauan Talaud Tahun 2014-2034, Kecamatan Salibabu diprioritaskan untuk Pengembangan dan Pengelolaan Kawasan Perikanan Tangkap karena potensi perikanan yang belum termanfaatkan \pm 23.104 Ton/Tahun. Tahun 2017, Kecamatan Salibabu menempati urutan tertinggi untuk total produksi perikanan di Kabupaten Kepulauan Talaud. Total produksi perikanan Kecamatan Salibabu sebesar 702,3 ton atau 11,79 \% dari keseluruhan produksi perikanan di Kabupaten Talaud. Dari total produksi tesebut 46,23 merupakan hasil produksi usaha soma pajeko. Mayoritas nelayan soma pajeko merupakan nelayan penuh yang mata pencaharian utamanya sebagai nelayan dan tidak memiliki pekerjaan lain. Masyarakat nelayan pada umumnya merupakan kelompok masyarakat yang relatif tertinggal secara sosial, ekonomi dan budaya bila dibandingkan dengan kelompok masyarakat lainnya. Demikian juga berlaku untuk masyarakat nelayan soma pajeko di Kecamatan Salibabu dimana penghasilan nelayan dibawah upah minimum Kabupaten kepulauan Talaud sebesar Rp. 1.500.000,-. Masyarkat nelayan soma pajeko di Kecamatan Salibabu masih terbelenggu oleh kemiskinan. Oleh karena itu dengan maksud bisa keluar dari kondisi tersebut perlu ada intervensi ekternal sebagai suatu dorongan untuk memberdayakan mereka.

Penelitian ini menggunakan metode deskriptif, yaitu suatu metode dalam meneliti sekelompok manusia, suatu objek, suatu set kondisi, suatu system pemikiran ataupun suatu kelas peristiwa pada masa sekarang. Jenis data yang
\end{abstract}


dikumpulkan terdiri dari data primer dan data sekunder. Pengumpulan data dilakukan melalui wawancara secara mendalam terhadap responden, pengisian kuesioner dan studi kepustakaan. Responden terdiri dari masyarakat nelayan soma pajeko di Kecamatan Salibabu. Analisis data menggunakan metode deskriptif untuk mengetahui kehidupan sosial ekonomi masyarakat dan analisis mengunakan rumus pendapatan digunakan untuk menganalisis tingkat pendapatan masyarakat nelayan soma pajeko.

Hasil penelitian menunjukkan bahwa pendapatan bersih juragan soma pajeko di Kecamatan Salibabu rata- rata berkisar Rp86.784.000,-/tahun dan Rp. 10.608.840,-/tahun untuk pendapatan bersih masanae dengan hasil tangkapan utama berupa ikan Cakalang, Ikan Layang dan Ikan Tongkol.

Kata kunci: Nelayan Soma Pajeko, Kecamatan Salibabu dan Tingkat Pendapatan

\section{PENDAHULUAN}

Membangun Indonesia dari pinggiran dengan memperkuat daerahdaerah dan desa dalam kerangka negara kesatuan merupakan salah satu nawa cita ke-3 dalam RPJMN 20152019. Dalam RPJMN disebutkan bahwa ke depan secara khusus akan dilakukan pula percepatan pembangunan ekonomi nasional berbasis maritim (kelautan) dengan memanfaatkan sumberdaya kelautan dan jasa maritim, yaitu peningkatan produksi perikanan, pengembangan energi dan mineral kelautan, pengembangan kawasan wisata bahari dan kemampuan industri maritim dan perkapalan.

Selaras dengan itu dalam Renstra KKP 2015-2019 juga menyebutkan salah satu kebijakan pokok yang dilakukan adalah menerapkan prinsip-prinsip pengelolaan kelautan dan perikanan yang bertanggung jawab, berdaya saing dan berkelanjutan. Salah satu strategi dan langkah operasional yang dilakukan adalah membantu kemandirian pulaupulau kecil melalui pembangunan sentra kelautan dan perikanan terintegrasi di pulau-pulau kecil terluar serta promosi dan investasi pemanfaatan pulau-pulau kecil. Salah satu langkah operasional yang dilakukan adalah sinergi kegiatan di kawasan/sentra perikanan terpadu/minapolitan/sentra bisnis perikanan rakyat berbasis pulau-pulau kecil.

Dalam Peraturan Daerah Provinsi Sulawesi Utara No. 1 tahun
2017 pasal 12 tentang rencana zonasi wilayah pesisir dan pulau-pulau kecil Provinsi Sulawesi Utara tahun 20172037, Kabupaten Kepulauan Talaud ditetapkan sebagai lokasi Sentra Kelautan dan Perikanan Terpadu. Lokasi Sentra Kelautan Perikanan Terpadu (SKPT) Talaud terletak di Kecamatan Salibabu, di mana pada Perda RTRW (Rencana Tata Ruang Wilayah) No. 1 Tahun 2014 tentang Rencana Tata Ruang Wilayah Kab. Kepulauan Talaud Tahun 2014-2034, Kecamatan Salibabu diutamakan untuk pengembangan dan pengelolaan kawasan perikanan tangkap.

Kecamatan Salibabu merupakan salah satu kecamatan yang terletak di Kabupaten Kepulauan Talaud Sulawesi Utara, di mana Kecamatan ini akan dikembangkan sebagai kawasan minapolitan tangkap perikanan dan kelautan. Kawasan minapolitan adalah kawasan ekonomi berbasis kelautan dan perikanan yang terdiri dari sentra-sentra produksi jasa dan perdagangan serta kegiatan lainnya yang saling terkait satu dengan lainnya. Perikanan tangkap di Kabupaten Talaud sangat prospektif, sehingga harus dikembangkan secara maksimal. Tahun 2017, Kecamatan Salibabu menempati urutan tertinggi untuk total produksi di Kabupaten Kepulauan Talaud. Total produksi hasil perikanan Kecamatan salibabu sebesar 702,3 ton atau $11,79 \%$ dari keseluruhan produksi perikanan di Kabupaten Kepulauan Talaud. Dari total produksi 
hasil perikanan kecamatan salibabu sebesar 702,3 ton, 46, 23 \% merupakan hasil dari usaha soma pajeko.

Nelayan soma pajeko di Kecamatan Salibabu merupakan kelompok masyarakat pesisir yang hidup berkelompok. Mayoritas nelayan soma pajeko merupakan nelayan penuh yang mata pencaharian utamanya sebagai nelayan dan tidak memiliki pekerjaan lain. Masyarakat nelayan pada umumnya merupakan kelompok masyarakat yang relatif tertinggal secara sosial, ekonomi dan budaya bila dibandingkan dengan kelompok masyarakat lain (Kusnadi, 2003). Demikian juga untuk masyarakat nelayan soma pajeko di Kecamatan Salibabu, di mana dengan kekayaan alam yang dimiliki khususnya sumberdaya perikanan yang melimpah, masyarakat nelayan soma pajeko di Kecamatan salibabu khususnya anak buah kapal/masanae masih terbelenggu oleh kemiskinan. Penghasilan rata- rata mereka masih jauh di bawah upah minimum Kabupaten Talaud sebesar Rp. 1.500.000,-. Berdasarkan pemahaman tersebut maka penelitian ini dipandang perlu untuk dilakukan guna menganalisis tingkat pendapatan nelayan modern soma pajeko di Kecamatan Salibabu Kabupaten Kepulauan Talaud.

\section{METODOLOGI}

Penelitian ini dilakukan di
Kecamatan Salibabu Kabupaten
Kepulauan Talaud, Provinsi Sulawesi Utara. Penelitian dilakukan selama 4 (empat) bulan dimulai sejak bulan September 2017 sampai dengan bulan Desember 2017. Metode yang digunakan dalam penelitian ini adalah metode deskriptif, yaitu suatu metode dalam meneliti status sekelompok manusia, suatu obyek, suatu set kondisi, suatu system pemikiran, ataupun suatu kelas peristiwa pada masa sekarang. Tujuan dari penelitian deskritif ini adalah untuk membuat deskripsi, gambaran atau lukisan secara sistematis, faktual dan akurat mengenai fakta-fakta, sifatsifatserta hubungan antar fenomena yang diselidiki (Nazir, 2005).

Teknik pengumpulan data dalam penelitian ini yaitu berupa wawancara secara mendalam, penyebaran kuesioner dan studi pustaka

Adapun responden target adalah Masyarakat nelayan soma pajeko di kecamatan Salibabu. Sedangkan untuk data sekunder diperoleh dari Kantor Kecamatan Salibabu, kantor Dinas Perikanan Kabupaten Kepulauan Talaud dan Studi Pustaka.

\section{ANALISIS DATA}

Kadariah (1995) menyatakan pendapatan dan kelayakan suatu usaha digunakan analisis finansial dengan menggunakan formula rumus yang terdiri dari :

1. Operatif Profit, yaitu keuntungan usaha soma pajeko yang merupakan selisih antara pendapatan kotor dengan biaya tetap.

$$
\begin{aligned}
& \mathrm{OP}=\mathrm{TR}-\mathrm{VC} \\
& \text { Di mana : } \mathrm{OP}=\text { Keuntungan } \\
& \text { usaha soma pajeko } \\
& \mathrm{TR}=\quad \text { Total } \\
& \text { Penerimaan } \\
& \text { VC = Biaya Variabel }
\end{aligned}
$$

2. Total Keuntungan (Total Profit), yaitu keuntungan absolut yang merupakan selisih antara seluruh penerimaan atau hasil penjualan dengan seluruh pengeluaran.

$$
\pi=\mathrm{TR}-\mathrm{TC}
$$

Di mana: $\pi \quad=$ Total 


$$
\begin{aligned}
& T R=\text { Total Revenue } \\
& T C=\text { Total Cost }
\end{aligned}
$$

3. Profit Rate, yaitu keuntungan yang menunjukkan kemampuan suatu usaha dalam memberikan keuntungan jika dibandingkan dengan jumlah keseluruhan biaya yang dikeluarkan.

$$
\frac{\pi}{T C} \times 100 \%
$$

Di mana : $\pi \quad=$ Total Profit

$$
\mathrm{TC}=\text { Total Cost }
$$

4. Benefit Cost Ratio, yaitu perkiraan manfaat yang diharapkan pada waktu atau rasio penerimaan dengan seluruh pengeluaran

$$
\mathrm{BCR}=\frac{\text { Hasil Penjualan }(T R)}{\text { Biaya Total }(T C)}
$$

5. Jangka waktu pengembalian investasi (Payback Period/PP)

$$
\begin{aligned}
& \mathrm{PP}=\frac{I X 1 \text { Tahun }}{\pi} \\
& \text { Di mana: } I \quad=\text { Investasi } \\
& \pi=\text { Total Profit }
\end{aligned}
$$

6. Break Event Point, yaitu titik pulang pokok.
a. BEP Penjualan $=\frac{F C}{1-\frac{V C}{T F}}$
b. BEP Satuan Hasil Penjūālan
Di mana : FC = Fixed Corga
$\mathrm{VC}=$ Variabel Cost
$\mathrm{TR}=$ Total Revenue

\section{HASIL DAN PEMBAHASAN}

\section{Analisis Pendapatan Nelayan Soma Pajeko}

A. Biaya Investasi (Cost Investment) Biaya investasi adalah dana yang tidak langsung dikonsumsi tapi berputar menghasilkan kembali penerimaan baru (Mantjoro, 1996). Biaya investasi dalam usaha soma pajeko berupa biaya yang dikeluarkan untuk mendapatkan barang investasi berupa kapal, mesin, alat tangkap, perahu lampu dan barang lainnya yang menghasilkan produksi.

Tabel 1. Biaya Investasi

\begin{tabular}{clrc}
\hline No & \multicolumn{1}{c}{ Uraian } & $\begin{array}{l}\text { Harga } \\
(\mathrm{Rp})\end{array}$ & Persentase $(\%)$ \\
\hline 1. & Kapal & 160.000 .000 & 29,62 \\
2. & Jaring & 200.000 .000 & 37,03 \\
3. & Perahu Lampu & 20.000 .000 & 3,7 \\
4. & 3 unit mesin tempel 40 PK @ Rp45.000.000 & 135.000 .000 & 25 \\
5. & Peralatan penanganan ikan & 25.000 .000 & 4,62 \\
\multicolumn{2}{c}{ Total Biaya Investasi } & 540.000 .000 & 100 \\
\hline
\end{tabular}

Sumber : Data Primer diolah, 2018

Tabel menunjukkan bahwa biaya investasi yang paling besar dikeluarkan untuk pembelian jaring, yaitu sebesar $37,03 \%$ dari total biaya investasi dan biaya paling kecil untuk pembelian peralatan penanganan ikan sebesar $4,62 \%$.

\section{B.Biaya Tetap (Fixed Cost)}

Biaya tetap terdiri dari biaya perawatan kapal, mesin, alat tangkap dan perahu lampu dan biaya penyusutan. Semua biaya tetap ditanggung oleh pemilik kapal (juragan). Perawatan dan pemeliharaan dilakukan setiap bulan pada saat tidak melakukan operasi penangkapan ikan di laut. 
Perawatan yamg dilakukan meliputi pengecatan, pendempulan bagianbagian kapal yang mengalami pengikisan, pembersihan kapal dari organisme yang menempel. Termasuk juga biaya pemeliharaan mesin berupa penggantian oli dan service mesin serta perbaikan jaring yang rusak, seperti menjahit atau menambal beberapa bagian jaring yang sobek.

Tabel 2. Biaya Tetap

\begin{tabular}{llcrrr}
\hline No & \multicolumn{1}{c}{ Uraian } & $\begin{array}{c}\text { Umur Ekonomis } \\
\text { (Tahun) }\end{array}$ & $\begin{array}{c}\text { Biaya Penyusutan } \\
\text { (Rp/Tahun) }\end{array}$ & $\begin{array}{c}\text { Biaya Perawatan } \\
\text { (Rp/Tahun) }\end{array}$ & \multicolumn{1}{c}{$\begin{array}{c}\text { Jumlah } \\
\text { (Rp/Tahun) }\end{array}$} \\
\hline 1. & Kapal & 4 & 40.000 .000 & 5.000 .000 & 45.000 .000 \\
2. & $\begin{array}{l}\text { Mesin Kapal } \\
\text { (3 buah) }\end{array}$ & 15 & 9.000 .000 & 3.500 .000 & 12.500 .000 \\
3. Alat tangkap/ & 5 & 7.000 .000 & 7.000 .000 & 14.000 .000 \\
$\quad \begin{array}{l}\text { Jaring } \\
\text { 4. Perahu lampu }\end{array}$ & 5 & 4.000 .000 & 2.000 .000 & 6.000 .000 \\
5. & Mesin perahu lampu & 7 & 500.000 & 500.000 & 1.000 .000 \\
& (1 buah) \\
$\quad$ Total Biaya Tetap & & & & 78.500 .000 \\
\hline
\end{tabular}

Sumber : Data Primer diolah, 2018

Berdasarkan tabel, diketahui bahwa biaya penyusutan merupakan biaya paling besar yang dikeluarkan setiap tahun berkisar Rp. 60.500.000,atau $77,07 \%$ dari total biaya tetap.
C.Biaya Tidak Tetap (Variable Cost)

Biaya tidak tetap (Variable Cost) adalah biaya yang langsung dihubungkan dengan lokasi penangkapan (fishing ground) dan lamanya waktu operasi penangkapan , yaitu keseluruhan biaya operasional penangkapan.

Tabel 3. Biaya Tidak Tetap

\begin{tabular}{|c|c|c|c|c|}
\hline No & Uraian & $\begin{array}{l}\text { Jumlah } \\
\text { (Liter) }\end{array}$ & $\begin{array}{l}\text { Total Biaya } \\
\text { (Rp) }\end{array}$ & $\begin{array}{c}\text { Persentase } \\
(\%)\end{array}$ \\
\hline 1. & Minyak Tanah & 18.000 & 90.000 .000 & 51,02 \\
\hline 2. & Premium & 1.200 & 12.000 .000 & 6,80 \\
\hline 3. & Oli & 960 & 38.400 .000 & 21,77 \\
\hline 4. & Perahu lampu & & 36.000 .000 & 20,41 \\
\hline \multicolumn{3}{|c|}{ Biaya Tidak Tetap } & 176.400 .000 & 100 \\
\hline
\end{tabular}

Berdasarkan tabel, diketahui bahwa keseluruhan biaya operasional dalam usaha soma pajeko di Kecamatan Salibabu adalah BBM sehingga harga BBM sangat mempengaruhi pendapatan nelayan. Semakin mahal harga BBM, maka pendapatan nelayan akan semakin berkurang. Nelayan pajeko di lokasi penelitian tidak membawa es balok karena lokasi fishing ground yang dekat sehingga waktu penangkapan singkat.
Waktu operasi penangkapan hanya satu hari (one day fishing), yaitu berangkat pada sore menjelang malam dan kembali pada pagi hari. Untuk konsumsi pada saat melakukan operasi penangkapan ditanggung oleh masingmasing nelayan.

\section{Total Biaya (Total Cost/TC)}

Total biaya merupakan biaya tetap ditambah dengan biaya tidak tetap. 
Total biaya dapat dilihat pada tabel berikut.

Tabel 4. Total Biaya

\begin{tabular}{cccc}
\hline No & Uraian & Biaya & Persentase \\
$($ Rp) & $(\%)$ \\
\hline 1. & Biaya Tetap & 78.500 .000 & 43,53 \\
2. & Biaya Tidak Tetap & 176.400 .000 & 56,47 \\
\multicolumn{2}{c}{ Total Biaya } & 254.900 .000 & 100 \\
\hline
\end{tabular}

Sumber : Data Primer diolah, 2018

Berdasarkan tabel 4, diketahui bahwa biaya tidak tetap (variable cost) yang dikeluarkan per tahunnya sebesar $56,47 \%$ lebih besar dibandingkan biaya tetap (fixed cost) yang dikeluarkan sebesar $43,53 \%$.

Tabel 5. Pendapatan Kotor

\begin{tabular}{|c|c|c|c|c|}
\hline No & Uraian & $\begin{array}{c}\text { Jumlah } \\
\text { (kg) }\end{array}$ & $\begin{array}{c}\text { Harga } \\
\text { (Rp) }\end{array}$ & Hasil Penjualan \\
\hline & Hasil Tangkapan & 105.000 & & \\
\hline & a. Ikan Layang & 39.900 & 6.000 & 239.400 .000 \\
\hline & b. Ikan Tongkol & 27.300 & 5.000 & 136.500 .000 \\
\hline & c. Ikan Cakalang & 37.800 & 10.000 & 378.000 .000 \\
\hline & Total Pendapatan Kotor & & & 753.900 .000 \\
\hline
\end{tabular}

Berdasarkan tabel, diketahui bahwa pendapatan kotor nelayan soma pajeko pertahun rata- rata sebesar $\mathrm{Rp}$. 753.900.000,- dengan produksi per tahun rata- rata berkisar $105.000 \mathrm{~kg}$. Harga ikan dilokasi penelitian bervariasi, yaitu untuk ikan Layang sebesar Rp. 6.000,- per kg, ikan Tongkol Rp. 5.000,-

\section{E. Pendapatan Kotor/ Total Penerimaan (Total Reveneu/TR) \\ Pendapatan kotor/total revenue} merupakan keseluruhan hasil produksi yang dikalikan dengan harga jual ikan di pasaran. Besar kecilnya pendapatan kotor yang diperoleh nelayan sangat bergantung pada jumlah hasil tangkapan dan harga ikan dipasaran. 
G. Total Keuntungan ( $\pi$ )

Total keuntungan merupakan total penerimaan dikurangi total biaya, dapat dilihat pada tabel berikut.

Tabel 7. Total Keuntungan ( $\pi)$

\begin{tabular}{|c|c|c|}
\hline No & Uraian & $\begin{array}{l}\text { Jumlah } \\
\text { (Rp) }\end{array}$ \\
\hline 1. & Total Penerimaan & 753.900 .000 \\
\hline 2. & Total Biaya & 254.900 .000 \\
\hline & Total Keuntungan $(\pi)$ & 499.000 .000 \\
\hline
\end{tabular}

Sumber : Data Primer diolah, 2018

Berdasarkan tabel, diketahui total keuntungan adalah Rp499.000.000,- yang didapatkan dari hasil perhitungan total penerimaan yang telah dikurangi dengan total biaya.

\section{H.Benefit Cost Ratio (BCR)}

Benefit Cost Ratio (BCR) yaitu perkiraan manfaat yang diharapkan pada waktu mendatang atau ratio penerimaan dengan seluruh pengeluaran. Apabila BCR $>1$ maka usaha tersebut layak dijalankan.

Tabel 8. Benefit Cost Ratio (BCR)

\begin{tabular}{clll}
\hline No & & \multicolumn{1}{c}{ Uraian } & $\begin{array}{c}\text { Total Biaya } \\
\text { (Rp) }\end{array}$ \\
\hline 1. & Total Penerimaan (TR) & 753.900 .000 \\
2. & Total Biaya (TC) & 254.900 .000 \\
& & Benefit Cost Ratio (BCR) & 2,95 \\
\hline
\end{tabular}

Sumber : Data Primer diolah, 2018

Berdasarkan tabel 8, diketahui bahwa nilai BCR lebih dari 1 yaitu 2,95. Hal ini berarti usaha soma pajeko di Kecamatan Salibabu layak untuk dijalankan.

I.Jangka Waktu Pengembalian (Payback Period /PP)

Analisis jangka waktu pengembalian/Payback Period (PP) bertujuan untuk mengetahui tingkat pengembalian investasi yang telah ditanamkan pada suatu usaha. Jika nilai Payback Period kurang dari 3 tahun berarti tingkat pengembailan modal pada usaha tersebut masuk dalam kategori cepat, jika Payback Period lebih dari 3 tahun dan kurang dari 5 tahun berarti tingkat pengembalian modalnya masuk kategori sedang dan jika Payback Period di atas 5 tahun maka tingkat pengembalian modal masuk kategori lambat.

Tabel 9. Payback Period (PP)

\begin{tabular}{clcc}
\hline No & \multicolumn{1}{c}{ Uraian } & $\begin{array}{c}\text { Total Biaya } \\
\text { (Rp) }\end{array}$ \\
\hline 1. & Biaya Investasi & 540.000 .000 \\
2. & Total Keuntungan & 499.000 .000 \\
& & Payback Period (Tahun) & 1,08 \\
\hline
\end{tabular}

Sumber : Data Primer diolah, 2018 
Berdasarkan tabel kriteria penilaian untuk pengembalian investasi (Payback Period) di atas, maka diketahui bahwa jangka waktu pengembalian usaha soma pajeko di Kecamatan salibabu tergolong cepat karena jangka waktu pengembalian modal kurang dari 3 tahun yaitu 1,08 tahun atau 1 tahun 29 hari. Dengan demikian usaha soma pajeko di Kecamatan Salibabu dapat diandalkan sebagai sumber utama pendapatan masyarakat nelayan dalam bidang perikanan.
J.Break Event Point (BEP)

Break Event Point (BEP) merupakan parameter analisis yang digunakan untuk mengetahui batas nilai produksi atau volume produksi pada soma pajeko mencapai titik impas, yaitu tidak untung atau tidak rugi. Pada keadaan ini keuntungan atau kerugian sama dengan nol. Nilai BEP (penjualan) dan nilai BEP (satuan) pada usaha soma pajeko.

Tabel 10. Break Event Point (BEP)

\begin{tabular}{|c|c|c|}
\hline No. & $\begin{array}{c}\text { Break Event Point } \\
\text { (BEP) }\end{array}$ & Jumlah \\
\hline 1. & BEP Penjualan (Rp) & 102.478 .181 \\
\hline 2. & BEP Satuan (kg) & $14.639,74$ \\
\hline
\end{tabular}

Sumber : Data Primer diolah, 2018

Artinya usaha soma pajeko akan mengalami titik impas apabila telah menjual ikan sebanyak $14.639,74 \mathrm{~kg}$ berdasarkan berat dengan harga jual ikan seharga Rp102.478.181,--.

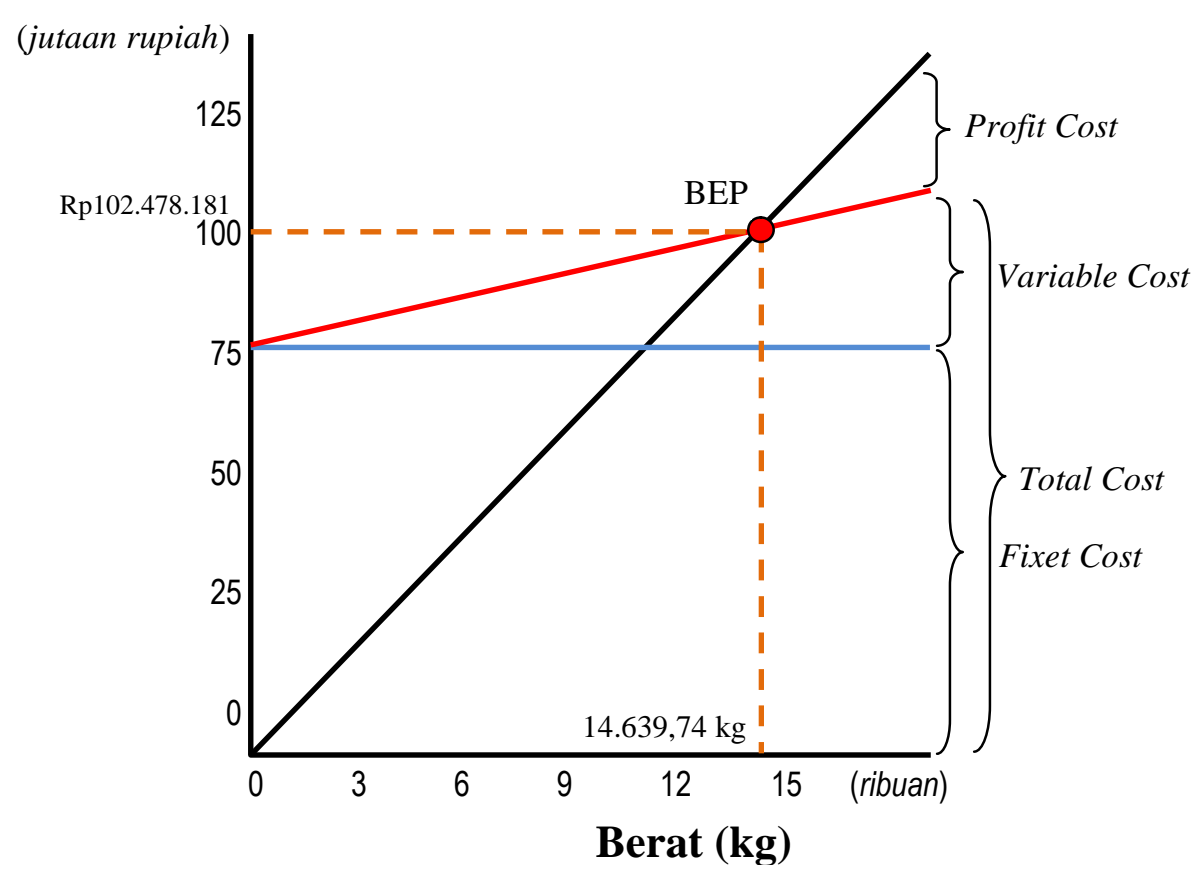

Gambar 4. Grafik BEP Usaha Soma Pajeko 


\section{Pendapatan Juragan}

Juragan atau pemilik kapal memiliki peran yang sangat penting dalam usaha soma pajeko, karena juragan bertanggung jawab terhadap kelayakan kapal dan alat tangkap sehingga operasi penangkapan ikan bisa berjalan dengan baik. Biasanya Juragan bertindak sebagai pemimpin operasi penangkapan. Berdasarkan hasil penelitian, Juragan soma pajeko di Kecamatan Salibabu semuanya terlibat dalam operasi penangkapan ikan di laut, artinya juragan merangkap juga sebagai masanae. Sehingga dalam sistem pembagian hasil, juragan yang merangkap masanae juga akan mendapatkan hasil yang lebih besar. Rata-rata pendapatan bersih untuk Juragan sebesar Rp76.175.000/tahun. Jika Juragan merangkap masanae, maka juragan akan mendapat bagian juga untuk masanae sehingga pendapatan bersih untuk Juragan yang merangkap masanae berkisar Rp86.784.000/tahun. Dalam usaha soma pajeko, biaya tetap ditanggung oleh Juragan selaku pemilik kapal.

Tabel 11. Pendapatan Juragan Usaha Soma Pajeko

\begin{tabular}{llccc}
\hline No. & Jabatan & $\begin{array}{c}\text { Pendapatan Kotor } \\
\text { (Rp/tahun) }\end{array}$ & $\begin{array}{c}\text { Biaya Tetap } \\
\text { (Rp/Tahun) }\end{array}$ & $\begin{array}{c}\text { Pendapatan Bersih } \\
\text { (Rp/tahun) }\end{array}$ \\
\hline 1. & Juragan & 212.175 .000 & 136.000 .000 & 76.175 .000 \\
2. & Juragan merangkap masanae & 222.784 .000 & 136.000 .000 & 86.784 .000 \\
\hline
\end{tabular}

Sumber : Data Primer diolah, 2018

\section{Pendapatan Anak Buah Kapal (masanae)}

Pendapatan anak buah kapal (masanae) sangat bervariasi. Hal ini disebabkan jumlah masanae yang ikut dalam oparasi penangkapan bervariasi dan hasil yang diperoleh juga bervariasi sehingga pendapatan yang diperoleh pasti juga akan berpengaruh karena pendapatan sangat ditentukan oleh banyaknya orang yang ikut dalam operasi penangkapan dan hasil yang diperoleh. Dalam operasi penangkapan ikan, jumlah masanae berkisar antara 15-20 orang. Jika masanae kurang dari 15 orang, maka kegiatan penangkapan ikan tidak bisa dilakukan karena dalam operasi penangkapan ikan soma pajeko membutuhkan tenaga yang besar untuk menata pemberat, menata pelampung dan menata dan menarik jaring. Berdasarkan hasil wawancara, terdapat 2 jenis masanae, yaitu masanae tetap dan masanae tidak tetap. Masanae tetap adalah masanae yang selalu ikut dalam operasi penangkapan ikan. Sedangkan masanae tidak tetap hanya sewaktuwaktu ikut dalam operasi penangkapan. Kadangkala mereka tidak ikut dalam operasi penangkapan karena melakukan operasi penangkapan ikan di tempat lain atau karena alasan tertentu. Tetapi dalam sistim pengupahan, baik masanae tetap maupun masanae tidak tetap semuanya diperlakukan sama, yaitu upah diberikan setiap kali ikut melaut.

Berdasarkan hasil penelitian, masanae merupakan kelompok yang memperoleh pendapatan jauh lebih kecil jika dibandingkan dengan pendapatan yang diperoleh juragan pemilik kapal. Pendapatan tersebut oleh masyarakat nelayan dikumpulkan dan disimpan di rumah. Oleh karena itu, agar pendapatan tersebut memiliki nilai tambah yang optimal, maka program utama yang perlu dilaksanakan adalah memberikan kredit khususnya kepada para buruh nelayan agar mereka 
memiliki kapal sendiri. Sehingga pendapatan tersebut dapat digunakan untuk mengansur pembayarannya. Selain itu, pilihan kebijakan lainnya adalah memberikan penyuluhan dan penyadaran kepada para nelayan agar mau membuka rekening tabungan, agar pendapatan tersebut lebih aman dan dapat memberikan keuntungan dalam bentuk bunga terhadap masyarakat nelayan. Dengan demikian, diharapkan masanae bisa memiliki kapal sendiri sehingga dapat meningkatkan pendapatan nelayan.

Tabel 12. Pendapatan Anak Buah Kapal (Masanae) Usaha Soma Pajeko

\begin{tabular}{cccc}
\hline Jabatan & Pendapatan bersih (Rp/trip) & Pendapatan bersih (Rp/bulan) & $\begin{array}{c}\text { Pendapatan bersih } \\
\text { (Rp/tahun) }\end{array}$ \\
\hline Masanae & 88.407 & 1.060 .884 & 10.608 .840 \\
\hline
\end{tabular}

Sumber : Data Primer diolah, 2018

Tabel 26. Perbandingan Pendapatan Bersih Juragan dan Masanae

\begin{tabular}{|c|c|c|c|c|}
\hline No. & Pendapatan Bersih & $\begin{array}{l}\text { Per Trip } \\
\text { (Rp) }\end{array}$ & $\begin{array}{l}\text { Per Bulan } \\
\text { (Rp) }\end{array}$ & $\begin{array}{l}\text { Per Tahun } \\
\text { (Rp) }\end{array}$ \\
\hline 1. & Juragan/ Pemilik Kapal & 634.792 & 7.617 .500 & 76.175 .000 \\
\hline 2. & Juragan merangkap masanae & 723.200 & 8.678 .400 & 86.784 .000 \\
\hline & Masanae & 88.407 & 1.060 .884 & 10.608 .840 \\
\hline
\end{tabular}

Sumber: Data primer diolah, 2018

\section{Sistem Bagi Hasil}

Sistem bagi hasil dalam usaha soma pajeko di Kecamaatan Salibabu merupakan hasil kesepakatan bersama antara Pemilik Kapal, Pemilik Rumpon dan Masanae yaitu hasil yang diperoleh dalam operasi penangkapan dikalikan dengan harga jual sehingga diperoleh pendapatan kotor. Pendapatan kotor yang diperoleh kemudian dikurangi dengan biaya operasional selama proses penangkapan sehingga diperoleh pendapatan bersih. Pendapatan bersih ini kemudian dibagi tiga secara merata umtuk pemilik kapal (juragan), pemilik rumpon dan masanae.

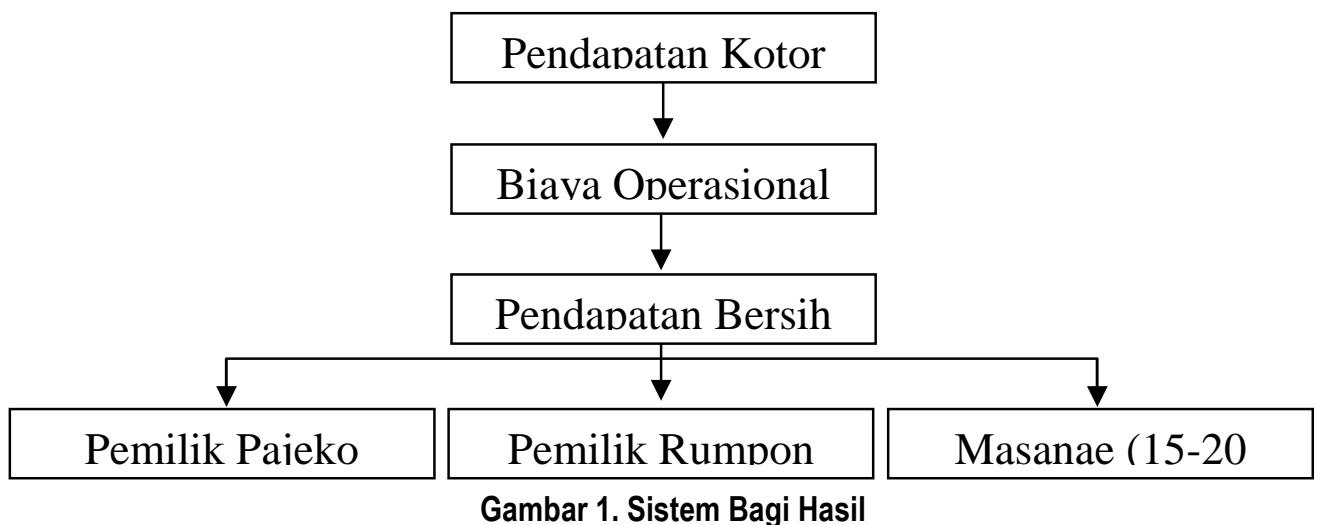

\section{Sistem Pemasaran Hasil Tangkapan}

Pada dasarnya sistem pemasaran hasil tangkapan pajeko sama untuk semua jenis kapal KM Berkat usaha, KM Malalugis dan KM Amalisa, yaitu setelah selesai melakukan operasi penangkapan, hasil tangkapan yang diperoleh kemudian ditimbang. Hasil tangkapan telah ditunggu oleh tibo-tibo dan transaksi penjualan kemudian dilakukan. Menurut Anisah dan Susiowati (2007), pola pemasaran dan distribusi ikan pada nelayan skala kecil tidak terlalu kompleks, hanya berpindah 2-3 kali sebelum sampai dikonsumen lokal. Demikian juga untuk sistem 
pemasaran yang ada di Kabupaten Talaud masih relatif sederhana dan terbatas seperti, yang dilakukan dalam 3 tahap :

1. Pemasaran hasil tangkapan dari nelayan ke pedagang tibo-tibo.

2. Oleh tibo-tibo, sebagian dijual ke pedagang eceran yang langsung menjualnya ke pasar atau menjual dari rumah ke rumah.

3. Sebagian dijual ke TPI di Manado dan jika hasil banyak dijual ke pabrik pengolahan ikan di Bitung. Ikan yang dijual diangkut melalui kapal laut.

Lebih jelasnya sistem pemasaran hasil tangkapan dapat dilihat pada Gambar 2.

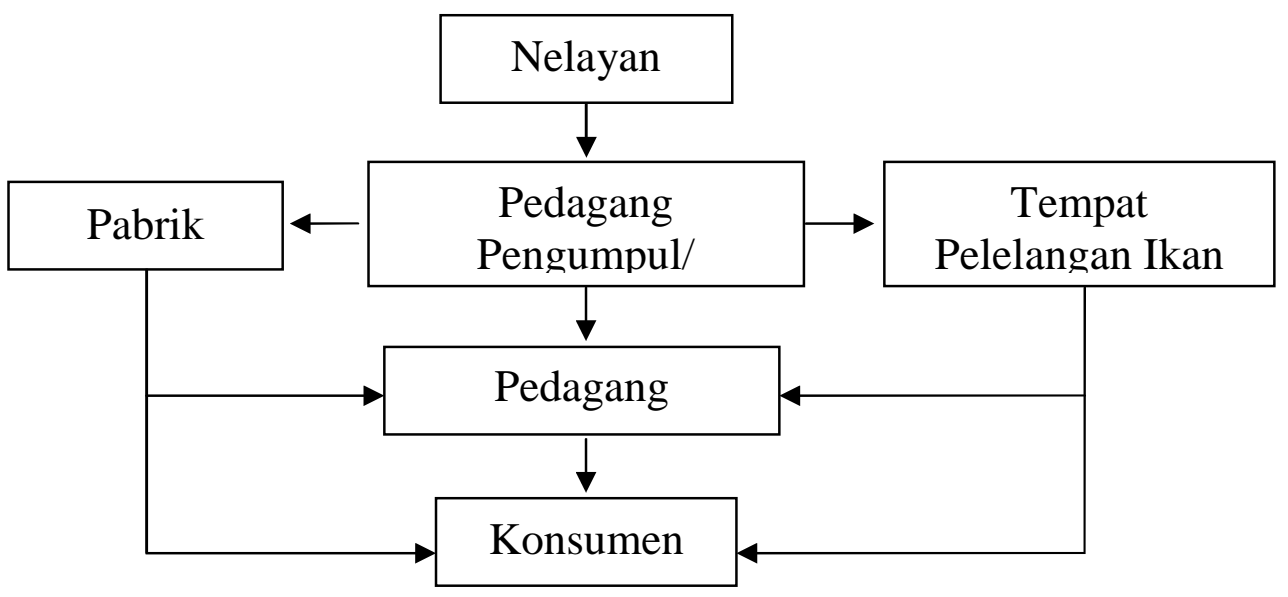

Gambar 2. Sistem pemasaran hasil tangkapan

\section{KESIMPULAN}

Pendapatan bersih Juragan Soma Pajeko di Kecamatan Salibabu rata-rata berkisar Rp86.784.000,-/tahun, Pendapatan Masanae Rp10.608.840,-Itahun dengan hasil tangkapan utama berupa ikan Cakalang, Ikan Layang dan Ikan Tongkol.

\section{SARAN}

Untuk mendorong peningkatan pendapatan nelayan perlu adanya peran pemerintah Kabupaten Talaud terutama Dinas Perikanan dengan bekerja sama dengan dinas terkait lainnya mencari solusi dari permasalahan yang dihadapi para nelayan, seperti akses pemasaran dan memberikan pembinaan untuk meningkatkan kemampuan menangkap ikan melalui peningkatan teknologi yang tepat guna.
DAFTAR PUSTAKA

Annisa, RN dan Susilowati, I.2007. Kajian Managemen Pemasaran Ikan Pindang Layang di Kota Tegal. Jurnal Pasir Laut 3 (I) : 1-18

Badan Perencanaan dan Pembangunan Daerah (BAPPEDA) Provinsi Sulawesi Utara, 2016.

Perda No 1 Tahun 2014 tentang Rencana Tata Ruang Wilayah Provinsi Sulawesi Utara Tahun 2014- 2034. Manado.

Kadariah, Karlina, L dan Gray, C. 1995. Pengantar Evaluasi Proyek. Lembaga Penerbit FE-UI. Jakarta.

Kusnadi. 2003. Akar Kemiskinan Nelayan: LKiS Pelangi Aksara. Yogyakarta

Kusnadi. 2006. Filosofi Pemberdayaan Masyarakat Pesisir. Humaniora. Bandung.

Mantjoro. 1996. IImu Ekonomi Bisnis Kelautan. Laboratorium Ekonomi dan Bisnis Perikanan, Fakultas Perikanan Universitas Sam Ratulangi. Seri Dokumentasi dan Publikasi IImiah, Dharma Pendidikan.

Nazir, Moh. 2005. Metode Penelitian. Jakarta. Ghalia Indonesia.

Perda Provinsi Sulawesi Utara No 1 Tahun 2017 tentang Rencana Zonasi Wilayah Pesisir dan

Pulau- Pulau Kecil. https: // Peraturan. Bpk. Go.id/home/details/49994.Diakses tanggal 15 februari 2018. 
Available online :http://ejournal.unsrat.ac.id/index.php/akulturasi 